\title{
The Efficacy of Pulsed Electromagnetic Field Therapy for Treating Knee Osteoarthritis: A Systematic Review
}

\author{
Leon Scott* \\ Division of Sports Medicine, Vanderbilt University Medical center, US \\ *Corresponding author: Leon Scott, Assistant Professor, Division of Sports Medicine, Vanderbilt University Medical center, Spring \\ Hill, US. \\ To Cite This Article: Leon Scott. The Efficacy of Pulsed Electromagnetic Field Therapy for Treating Knee Osteoarthritis: A Systematic Review. \\ Am J Biomed Sci \& Res. 2019 - 3(2). AJBSR.MS.ID.000648. DOI: 10.34297/AJBSR.2019.03.000648
}

Received: April 24, 2019 | Published: May 28, 2019

\begin{abstract}
Objective: Past systematic reviews and meta-analysises of older studies of pulsed electromagnetic field (PEMF) therapy report positive effect sizes favoring treatment over control. This systematic review was conducted to include the most recent studies and evaluate the clinical significance of PEMF compared to control.
\end{abstract}

Data sources: A systematic review of PubMed, EMBASE, and the Cochrane controlled trials Register.

Methods: Level one and two trials reporting comparison of pulsed electromagnetic fields with placebo or other control were included. Mean differences were compared to the minimal clinically important differences (MCID) of functional and pain outcome scores.

Results: Ten studies, including 495 patients, showed a VAS difference between groups of 11 points out of 100, and a WOMAC difference between groups of 9.7 points out of 100 . groups.

Conclusion: PEMF is unlikely to make a clinically important difference in knee osteoarthritis pain and function compared to placebo and control Keywords: Pulsed electromagnetic field; Knee; Osteoarthritis; Systematic review

\section{Introduction}

Knee osteoarthritis is a common ailment, impacting greater than $15 \%$ of adults over 45 years old. The associated chemical inflammation and degradation of the articular surface is associated with pain, stiffness and loss of function. Common treatments include weight-loss in overweight patients, physical therapy including weight-bearing exercise, oral medications, injectable treatments and arthroplasty. Pulsed electromagnetic field therapy is a less common, non-pharmacologic treatment option [1].

PEMF devices are solenoids. Through the electromagnetic properties of electric current in a coiled wire, create a magnetic field that can induce a current in a neighboring material. This is the same principle used in common devices like wireless phone charging stations. Pulsing the current in the original solenoid, and the resulting pulsed magnetic field, create a pulsed voltage potential. Electromagnetic bone stimulators use these principles, and demonstrate associated changes in osteoblast activity and subsequent closure of non-union fractures. In vitro studies also found changes in the synthesis of glycosaminoglycans from chondrocytes in porcine knee joints.
Although not a common treatment for osteoarthritis, PEMF is the subject of three past systematic reviews and meta- analyses. All three cautiously support the use PEMF to improve knee function, and only one supports PEMF use for knee pain. Reported effect sizes were small and have the disadvantage of being difficult for clinicians to interpret for patients. The purpose of this systematic review was to

1. Include the newest trials in a systematic review and to

2. Report on the clinical responsive of a patient pain and function using the minimal clinically important difference (MCID).

Effect size is a statistical tool used to determine the difference in pooled groups before and after an intervention, calculated from the difference in pooled means and a denominator derived from the standard deviations. It is akin to the statistically significant differences between pooled group. The MCID is the average magnitude of change that must occur in a functional test, like a patient-reported outcome, before it is considered a meaningful 
difference. The MCID is akin to the clinically significant difference and is derived from longitudinal validity studies. The MCID values for the visual analog score (VAS) and the Western Ontario Methods and McMasters Universities Osteoarthritis Index (WOMAC) are established values; 20 out of $100 \mathrm{~mm}$ and 12 points out of 100 , respectively.

\section{Information sources}

\section{Figure 1: Study Flow Diagram}

The author performed a systematic online review of PubMed, EMBASE, and the Cochrane Controlled Trial Register. The search terms used were "pulsed electromagnetic field"," osteoarthritis, and "knee osteoarthritis." The bibliographies of identified reports, systematic reviews/meta-analyses and published clinical reviews were also searched for additional papers. The searches ended October 1, 2018. The subsequent eligibility criteria and study selection are displayed in the study flow diagram (Figure 1).

\section{Eligibility criteria \& study selection}

A single reviewer (LS) screened the candidate papers for specific inclusion criteria. This screening was limited to Englishlanguage, randomized control trials and prospective cohorts trials that evaluate the use of pulsed electromagnetic field devices for the treatment of osteoarthritis in the knee. The study populations were adults with osteoarthritis determined by radiographic and clinical criteria, excluding inflammatory arthritis. Interventions were limited to low pulsed frequencies, from $50 \mathrm{~Hz}$ to $1000 \mathrm{~Hz}$. This determination was to avoid ranges commonly associated with

\begin{tabular}{|c|c|c|c|c|c|c|c|c|}
\hline & \multirow{2}{*}{$\begin{array}{c}\text { Study design } \\
\text { Design }\end{array}$} & \multirow[b]{2}{*}{ Comments } & \multirow{2}{*}{$\begin{array}{c}\text { Total } \\
\begin{array}{c}\text { PEMF } \\
\mathbf{n}\end{array}\end{array}$} & \multicolumn{3}{|c|}{ Age } & \multirow{2}{*}{$\begin{array}{c}\text { \% Male } \\
\text { PEMF }\end{array}$} & \multirow[b]{2}{*}{ Control } \\
\hline & & & & $\begin{array}{c}\text { Control } \\
\mathbf{n}\end{array}$ & $\begin{array}{c}\text { PEMF } \\
\text { Ave (SD) }\end{array}$ & $\begin{array}{c}\text { Control } \\
\text { Ave (SD) }\end{array}$ & & \\
\hline $\begin{array}{l}\text { Bagnato et } \\
\text { al. [8] }\end{array}$ & DBRCT & & 30 & 30 & $69(12)$ & $67(10)$ & 30 & 27 \\
\hline $\begin{array}{c}\text { Dundar et al. } \\
{[9]}\end{array}$ & RCT & $\begin{array}{c}\text { No statement on patient } \\
\text { blinding }\end{array}$ & 20 & 20 & 57 (14.5) & $58(14)$ & 30 & 25 \\
\hline $\begin{array}{c}\text { Iannitti et al. } \\
{[11]}\end{array}$ & PC & $\begin{array}{l}\text { Right knee received active } \\
\text { treatment, left knee received } \\
\text { the control treatment }\end{array}$ & 28 & 28 & $70(8.0)$ & $70(8.0)$ & - & - \\
\hline
\end{tabular}

radiofrequencies $(>4000 \mathrm{~Hz})$, which may have different physiologic effects, if any at all. Also, low frequency pulsed magnetic waves are commonly used in orthopedics tools like bone stimulators. Comparison groups were limited to placebo or common therapies for knee osteoarthritis including standardized physical therapy. All studies needed to present results that included patient reported outcomes, validated for knee osteoarthritis, including visual analog scores (VAS) for pain and functional measures including the Western Ontario McMasters Universities Osteoarthritis Index (WOMAC). All studies are from after 2000 to ensure the most recent clinical trials. Other systematic reviews are limited to studies up to 2005 only.

Abstracts were reviewed to complete this screening. When abstracts did not have sufficient information, the methods and materials for each study was reviewed. Trials that were not available online to download, reviews, meta- analyses, in-vitro studies and commentaries were then remove, leaving ten trials for this systematic review. The characteristics of the studies, the populations, and treatments are in (Tables 1\&2). 


\begin{tabular}{|c|c|c|c|c|c|c|c|c|}
\hline $\begin{array}{l}\text { Nelson et al. } \\
\text { [10] }\end{array}$ & DBRCT & & 12 & 12 & $56(2.5)$ & $58(2.5)$ & - & - \\
\hline $\begin{array}{c}\text { Ozguclu et al. } \\
\text { [12] }\end{array}$ & DBRCT & & 20 & 20 & $61(7.7)$ & $62(8.2)$ & - & - \\
\hline Ay et al. [13] & RCT & $\begin{array}{l}\text { No statement on patient } \\
\text { blinding }\end{array}$ & 27 & 20 & $59(8.8)$ & $58(6.5)$ & 30 & 24 \\
\hline $\begin{array}{l}\text { Laufer et al. } \\
\quad 2005\end{array}$ & PC & & 27 & 31 & $73(6.7)$ & $73(6.9$ & 9 & 34 \\
\hline $\begin{array}{c}\text { Thamsborg et } \\
\text { al. [14] }\end{array}$ & DBRCT & & 42 & 41 & $60(8.7)$ & $60(8.6)$ & 39 & 53 \\
\hline $\begin{array}{l}\text { Callaghan et al. } \\
\qquad 2005\end{array}$ & DBRCT & & 9 & 9 & $63.5(7.9)$ & $58(7.3)$ & 56 & 44 \\
\hline $\begin{array}{c}\text { Pipitone et al. } \\
\text { [15] }\end{array}$ & DBRCT & & 34 & 35 & 62 & 64 & 65 & 80 \\
\hline
\end{tabular}

Note: $\mathrm{DBRCT}=$ Double blind randominzed control trial, $\mathrm{RCT}=$ Randomized control trial, $\mathrm{PC}=$ Prospective cohort.

Table 2: Characteristics of the treatment.

\begin{tabular}{|c|c|c|c|c|c|c|}
\hline & PEMF & \multirow[b]{2}{*}{$\begin{array}{c}\text { Magnetic field } \\
\text { strength } \\
\text { microT }\end{array}$} & \multirow[b]{2}{*}{$\begin{array}{c}\text { Tissue voltages } \\
\mathrm{mv} / \mathrm{cm}\end{array}$} & \multirow[b]{2}{*}{ Time } & \multirow[b]{2}{*}{ Additional treatments } & \multirow[b]{2}{*}{ Control } \\
\hline & $\begin{array}{c}\text { Frequency } \\
\mathrm{Hz}\end{array}$ & & & & & \\
\hline Bagnato & 1000 & 0.03 & & $\begin{array}{c}12 \text { hours/day x } \\
7 \text { days/week x } 4 \\
\text { weeks }\end{array}$ & & Placebo \\
\hline Dundar & 50 & 100 & & $\begin{array}{l}20 \min \times 5 \text { days/ } \\
\text { week } x 4 \text { weeks }\end{array}$ & PT/TENS/Heat & $\begin{array}{c}\text { Placebo + PT / TENS/ } \\
\text { Heat }\end{array}$ \\
\hline Iannitti & $6-100$ & 5000 & & $\begin{array}{l}30 \text { min } \times 3 \text { days/ } \\
\text { week } \times 6 \text { weeks }\end{array}$ & NSAID & NSAID \\
\hline Nelson & & 140 & 340 & $\begin{array}{l}30 \text { min } \times 7 \text { days/ } \\
\text { week x } 6 \text { weeks }\end{array}$ & & Placebo \\
\hline Ozguclu & 50 & 3000 & & $\begin{array}{l}30 \text { min } \times 5 \text { days/ } \\
\text { week x } 2 \text { weeks }\end{array}$ & $\begin{array}{c}20 \text { min hot pack + } 5 \text { min US } \\
+ \text { isometric HEP }\end{array}$ & $\begin{array}{l}20 \text { min hot pack + } 5 \\
\text { min US + isometric HEP }\end{array}$ \\
\hline Ay & 50 & 105 & & $\begin{array}{l}30 \min \times 5 \text { days/ } \\
\text { week } \times 3 \text { weeks }\end{array}$ & PT/TENS/Heat & $\begin{array}{c}\text { Placebo + PT / TENS/ } \\
\text { Heat }\end{array}$ \\
\hline Laufer & 300 & & & $\begin{array}{l}60 \text { min } \times 7 \text { days/ } \\
\text { week } \times 3 \text { weeks }\end{array}$ & & Placebo \\
\hline Thamsborg & 50 & & $1-100$ & $\begin{array}{l}120 \text { min } \times 7 \text { days/ } \\
\text { week x } 6 \text { weeks }\end{array}$ & & Placebo \\
\hline Callaghan & 400 & & & $\begin{array}{l}20 \text { min } \times 3 \text { days/ } \\
\text { week x } 2 \text { weeks }\end{array}$ & & Placebo \\
\hline Pipitone & $3-7.8$ & 50 & & $\begin{array}{l}30 \text { min } \times 7 \text { days / } \\
\text { week x } 6 \text { weeks }\end{array}$ & & Placebo \\
\hline
\end{tabular}

\section{Data extraction}

The author extracted data using an institutional systematic review (Appendix 1).

\section{Risk for bias}

The papers were reviewed for selection bias - random sequence generation and allocation concealment, performance bias related to blinding, detection bias, attrition bias, and other forms of bias including selective reporting, funding sources or other biases not previously covered. (Table 3) shows the bias assessment for each paper. Either the paper clearly stated the methods used to mitigate bias $(+)$ or the paper either failed to protect against a form of bias, or omitted a statement all together (-). 
Table 3: Risk of bias.

\begin{tabular}{|c|c|c|c|c|c|c|c|c|c|} 
& Bagnato & Dundar & Iannitti & Nelson & Ozguclu & Ay & Laufer Thamsborg & Callaghan & Pipitone \\
\hline Random sequence generation & + & - & - & - & + & + & -- & + & + \\
\hline Allocation concealment & + & - & - & - & + & - & -- & + & + \\
\hline $\begin{array}{c}\text { Blinding of participants \& person- } \\
\text { nel }\end{array}$ & + & - & - & + & + & + & -+ & + & + \\
\hline $\begin{array}{c}\text { Blinding of outcome assessment } \\
\begin{array}{c}\text { Complete data sets \& }>70 \% \text { of } \\
\text { participants assessed }\end{array}\end{array}$ & + & + & + & + & + & + & -- & + & + \\
\hline Other bias & + & + & - & + & + & + & -+ & - & + \\
\hline
\end{tabular}

\section{Synthesis of results}

Being a systematic review, and not a meta-analysis, this paper will report of the trend in functional outcomes without forest plots or reported effect sizes.

\section{Results}

Ten trials were included using the methods noted previously (Figure 1). Four of these studies have not been included in any previous systematic reviews or meta-analyses.

The outcomes are displayed in an effort to simplify and standardize the reported pain and functional changes in the trials (Table 4). The VAS and WOMAC total scores are normalized to a 100-point scale. The changes in outcomes from baseline to final follow-up are reported. The outcomes are shortened to two significant figures. Standard deviations and confidence intervals were not converted to the normalized 100-point scale, and not included the (Table 4). The author did not have access to statistical programs to ensure accurate conversion of the variances. Statistically significant differences between the treatment and control groups are reported, as well [2-7].

\section{Vas}

Seven of the studies reported VAS as a clinical outcome. The average change in the VAS score in the PEMF treatment groups was 26 out of 100 points improvement (range 10-50). The average change in the control groups was 15 out of 100 points (range -5.032). Three of the seven studies report a statistically significant change in the VAS scores between the PEMF treatment groups and control groups. The PEMF treatment groups' average change from baseline exceeded the MCID, 20 out of 100 for VAS. However, only four of the seven trials reported a change in VAS in the PEMF treatment group that met or exceeded MCID. The average difference between PEMF treatment group and control groups did not reach the MCID, with only the lowest evidence study demonstrating a clinically significant difference between groups.

\section{Womac}

Seven of the studies reported WOMAC as a clinical outcome. The average change in the WOMAC score in the PEMF treatment groups was 14 out of 100 points improvement (range $0.0-52$ ). The average change in the control groups was 5.3 out of 100 points (range 0.3-15). Three of the seven studies report a statistically significant change in the WOMAC scores between the PEMF treatment groups and control groups. The PEMF treatment groups' average change from baseline exceeded the MCID, 12 out of 100 for WOMAC. However, only two of the seven trials reported a change in WOMAC in the PEMF treatment group that met or exceeded MCID. The average difference between PEMF treatment group and control groups did not reach the MCID, with only the lowest evidence study demonstrating a clinically significant difference between groups.

\begin{tabular}{|c|c|c|c|c|c|c|}
\hline & ?VAS & \multirow{2}{*}{ Control } & \multirow{2}{*}{ Diff } & ?WOMAC & \multirow{2}{*}{ Control } & \multirow{2}{*}{ Diff } \\
\hline & PEMF & & & PEMF & & \\
\hline Bagnato & 17 & 3 & Yes & 11 & 1.3 & Yes \\
\hline Dundar & 40 & 30 & No & 16 & 15 & No \\
\hline Iannitti & 50 & 11 & Yes & 52 & 8.3 & Yes \\
\hline Nelson & 27 & 11 & Yes & - & - & - \\
\hline Ozguclu & 24 & 32 & No & 7.9 & 7.9 & No \\
\hline Ay & 16 & 20 & No & - & - & - \\
\hline Laufer & - & - & - & 0 & 0.3 & No \\
\hline Thamsborg & - & - & - & 3.7 & 3.2 & No \\
\hline Callaghan & 10 & -5 & No & - & - & - \\
\hline Pipitone & - & - & - & 5.1 & 1 & Yes \\
\hline
\end{tabular}

Note: Diff = statistically significant difference between the PEMF and control groups. 


\section{Discussion}

\section{Summary of evidence}

The primary finding from this systematic review is that PEMF does not create a clinically significant improvement in pain or function for patients with osteoarthritis relative to the control group. Although three of the four previously unanalyzed trials report statistically significant improvements in pain or function, and previous meta-analyses report statistically significant effect sizes in favor of PEMF for pain or function, clinical significance is likely not met using MCID as our measurement of responsiveness to treatment.

\section{Limitations}

Six issues limit the strength on evidence from this systematic review; the use of MCID, the absence of measures of dispersion in the results, the short duration of treatment, the variance between PEMF tools, and outlier results from one lower evidence trial [813].

The MCID is an accepted measure of how responsive a patient reported outcome is for a given clinical issue. The primary benefit is the ability to communicate the average expected benefit a person would experience from an intervention because the measure is validated longitudinally in similar populations. However, the MCID often varies based on the amount of time has elapsed since an intervention occurred, with studies demonstrating varying values at 2,6 , and 12 months out from an intervention to treat knee osteoarthritis. The method for calculating the MCID also has various methods, yielding different results. These are two reasons why many advocate for the use of effect size calculations, which only rely on the data set used, and not subject to the validity of outside studies.

The trials run for no longer than 6 weeks. It is possible that longer trials of treatment could expose a clinically significant difference between treatment groups. Unfortunately, none of the studies elected to treat for a longer duration.

Another limitation is reporting only an average change in the outcomes, without reporting the measures of dispersion (e.g. standard deviation confidence intervals). However, the fact that the average difference between groups did not meet the MCID already satisfies the objection of this report; PEMF does not create a clinically significant improvement in the clinical outcome scores of patients with knee osteoarthritis.

The PEMF tools appear to have a significant amount of variance in the technical specifications (Table 3) and intended methods of action. Two of the studies (Callaghan et al. \& Laufer et al.) use devices which have the effect of creating heat within the treated body-part, while the other studies use devices that do not create an appreciable sensation of heat in the body during the treatment. Bagnato et al. [8] tested a device the a magnetic field three orders of magnitude weaker than the next lowest recorded device. It is difficult to reconcile that this variance in PEMF devices allows them to provide the same clinical impact or work through the same mechanism of action. It is possible that a subset of the PEMF tools has a positive statistically and clinically significant impact on knee osteoarthritis pain and function. However, this review cannot strongly support any one device [9-18].

In addition, Ianitti et al. [11] produced results that appeared to be lie outside of the range produced from the other included trials. That trial also used the lowest level of evidence study design in the grouping.

\section{Conclusions}

Pulsed electromagnetic field therapy is unlikely to provide a clinically significant improvement in pain or function in as measured with the MCID of VAS and WOMAC total scores in people with knee osteoarthritis.

\section{Funding}

There are not outside funding sources associated with this systematic review. There are no conflicts of interest to report.

\section{Acknowledgements}

I am grateful to the following for their help: Paul Meirick MD, Jason Williams MD, and David Neblett MD.

\section{References}

1. Jevsevar DS (2013) Treatment of Osteoarthritis of the Knee EvidenceBased Guideline (2 ${ }^{\text {nd }}$ Edn). J Am Acad Orthop Surg 21(9): 571-576.

2. Tubach F, Ravaud P, Baron G, Falissard B, Logeart I, et al. (2005) Evaluation of clinically relevant changes in patient reported outcomes in knee and hip osteoarthritis: the minimal clinically important improvement. Ann Rheum Dis 64(1): 29-33.

3. Greco NJ, Anderson AF, Mann BJ, Cole BJ, Farr J, et al. (2010) Responsiveness of the International Knee Documentation Committee Subjective Knee Form in comparison to the Western Ontario and McMaster Universities Osteoarthritis Index, modified Cincinnati Knee Rating System, and Short Form 36 in patients with focal articular cartilage defects. Am J Sports Med 38(5): 891-902.

4. Williams VI, Piva SR, Irrgang JJ, Crossley C, Fitzgerald GK (2012) Comparison of Reliability and Responsiveness of Patient-Reported Clinical Outcome Measures in Knee Osteoarthritis Rehabilitation. J Ortho Sports Phys Ther 42(8): 716-723.

5. Negm A, Lorbergs A, MacIntyre N (2013) Efficacy of low frequency pulsed subsensory threshold electrical stimulation vs placebo on pain and physical function in people with knee osteoarthritis: systematic review with meta-analysis. Osteoarthritis and Cartilage 21(9): 12811289.

6. Vavken P, Arrich F, Schuhfried O, Dorotka R (2009) Effectiveness of Pulsed Electromagnetic Field Therapy in the Management of Osteoarthritis of the Knee: A meta-analysis of Randomized Controlled Trials. J Rehabil Med 41(6): 406-411.

7. We SR, Koog YH, Jeong KI, Wi H (2013) Effects of pulsed electromagnetic field on knee osteoarthritis: a systematic review. Rheumatology (Oxford) 52(5): 815-824.

8. Bagnato GL, Miceli G, Marino N, Sciortino D, Bagnato GF (2016) Pulsed electromagnetic fields in knee osteoarthritis: a double blind, placebocontrolled, randomized clinical trial. Rheumatology (Oxford) 55(4): 755-762.

9. Dündar Ü, Aşık G, Ulaşlı AM, Sınıcı Ş, Yaman F, et al. (2016) Assessment of pulsed electromagnetic field therapy with Serum YKL-40 and ultrasonography in patients with knee osteoarthritis. Int J Rheum Dis 19(3): 287-293. 
10. Nelson FR, Zvirbulis R, Pilla AA (2013) Non-invasive electromagnetic field therapy produces rapid and substantial pain reduction in early knee osteoarthritis: a randomized double-blind pilot study. Rheumatol Int 33(8): 2169-2173.

11. Iannitti T, Fistetto G, Esposito A, Rottigni V, Palmieri B (2013) Pulsed electromagnetic field therapy for management of osteoarthritis-related pain, stiffness and physical function: clinical experience in the elderly. Clin Interv Aging 8: 1289-1293.

12. Ozgüçlü E, Cetin A, Cetin M, Calp E (2010) Additional effect of pulsed electromagnetic field therapy on knee osteoarthritis treatment: a randomized, placebo-controlled study. Clin Rheumatol 29(8): 927-931.

13. Ay S, Evcik D (2009) The effects of pulsed electromagnetic fields in the treatment of knee osteoarthritis: a randomized, placebo-controlled trial. Rheumatol Int 29(6): 663-666.

14. Thamsborg G, Florescu A, Oturai P, Fallentin E, Tritsaris K, et al. (2005) Treatment of knee osteoarthritis with pulsed electromagnetic fields: a randomized, double-blind, placebo-controlled study. Osteoarthritis Cartilage 13(7): 575-581.

15. Pipitone N, Scott DL (2001) Magnetic pulse treatment for knee osteoarthritis: a randomised, double-blind, placebo- controlled study. Curr Med Res Opin 17(3): 190-196.

16. Markov MS (2007) Pulsed electromagnetic filed therapy history, state of the art and future. Environmentalist 27(4): 465-475.

17. Chang SH, Hsiao Y, Lin H (2011) Low-frequency Electromagnetic Field Exposure Accelerates Chondrocytic Phenotype Expression on Chitosan Substrate. Orthopedics 34(1): 20.

18. Bassett CA, Pilla AA, Pawluk RJ (1977) A non-operative salvage of surgically-resistant pseudarthroses and non- unions by pulsing electromagnetic fields. A preliminary report. Clin Orthop Relat Res 124: 128-143. 